Check for updates

Cite this: RSC Adv., 2018, 8, 33361

Received 2nd August 2018

Accepted 18th September 2018

DOI: $10.1039 / \mathrm{c} 8 \mathrm{ra0} 0501 \mathrm{~b}$

rsc.li/rsc-advances

\title{
A biomimetic fluorescent chemosensor for highly sensitive zinc(II) detection and its application for cell imaging†
}

 \\ and Junjie Xiong*b
}

\begin{abstract}
To fabricate a novel biomimetic fluorescent chemosensor, PSaAEMA-co-PMPC was synthesized via atom transfer radical polymerization, and this copolymer could be used for the detection of zinc(I) and cell imaging. A series tests with various metal ions verified the specific fluorescence response behavior. This novel biomimetic fluorescent chemosensor exhibits excellent selectivity for $\mathrm{Zn}^{2+}$ ions over a wide range of tested metal ions in an aqueous solution. Moreover, cytotoxicity and bio-imaging tests were conducted to study the potential bio-application of the chemosensor. Owing to the biomimetic portion (phosphorylcholine), this copolymer possesses outstanding biocompatibility and could clearly image cells. The results indicated that PSaAEMA-CO-PMPC has great potential for application in zinc(॥) detection and cell imaging.
\end{abstract}

\section{Introduction}

Zinc, the second most abundant transition metal ion in the human body, is often present in a tightly bound form in proteins. It plays several significant roles in various fundamental biological processes. The disruption of Zn(II) homeostasis could lead to Parkinson's disease, Alzheimer's disease, immune dysfunction, and infantile diarrhea. ${ }^{1-5}$ As a consequence, the development of probes to effectively quantify and visualize $\mathrm{Zn}$ (II) concentration in biological systems is key to understanding the biological processes of $\mathrm{Zn}$ (II) in vivo.

Recently, there have been many studies on fluorescence probing methods and fluorescent chemosensors, such as the AIE probe technique, ${ }^{6-13}$ and fluorescent inorganic nanoparticles. ${ }^{14-18}$ Currently, there is great interest in the development of new methods with high sensitivity and the exploration of the role of $\mathrm{Zn}$ (II) in medicine and biology as well as the environment. Among the various types of methods, fluorescent chemosensors have attracted much attention due to their convenient use and high sensitivity, and could be employed to clarify the various biological functions of targeted metal cations in living cells. ${ }^{19-25} \mathrm{~A}$ few Zn(II) fluorescent chemosensors have been fabricated for physiological applications and some are

${ }^{a}$ Textile Institute, College of Light Industry, Textile and Food Engineering, Sichuan University, Chengdu, 610065, China.E-mail: scuchx@163.com

${ }^{b}$ Department of Pancreatic Surgery, West China Hospital, Sichuan University, Chengdu 610041, China. E-mail: junjiex2011@126.com

${ }^{c}$ State Key Laboratory of Biotherapy, Sichuan University, Chengdu 610041, China

† Electronic supplementary information (ESI) available. See DOI: 10.1039/c8ra06501b now commercially available. Salicylaldimine Schiff bases, one of the common structures, have aroused great interest for fluorescent chemosensors due to their facile synthesis and high binding affinity towards many metal ions. Salicylaldimine Schiff bases have poor fluorescence, but can display strong fluorescence once they coordinate with special metal ions such as zinc ions via the phenol oxygen atom and the imine nitrogen atom, which results in a rigid structure..$^{26}$ Until now, a large amount of small molecule fluorescent metal ion probes have been developed based on salicylaldimine Schiff bases in past decades. ${ }^{26-37}$ However, for the majority of them, their water solubility is very limited since these chemosensors are hydrophobic, which induces aggregation between them. Thus, detection could not be performed in pure water, and is often performed in mixed aqueous solutions with a certain portion of organic solvent. Furthermore, the accuracy and sensitivity of small molecule detection are not satisfactory. To this end, several elegant strategies have been developed to overcome the flaws of small molecule probes, for example conjugating or loading them into inorganic nanoparticles, micelles, polymers, and so forth. ${ }^{38-43}$ Of all of the above, polymer-based fluorescent chemosensors have several advantages over the others, such as water solubility, exceptional processability, and signal amplification. Hence, efforts have been dedicated to the fabrication of polymeric chemosensors, which contain salicylaldimine Schiff bases. Theato et al. prepared thermo- and light-responsive copolymers by grafting salicylaldehyde to amine pendantfunctionalized polymers. ${ }^{44}$ Cai et al. synthesized block copolymers and constructed a variety of coordinated polymeric aggregates with different metal ions. ${ }^{45-47}$ Zhang et al. constructed well-defined polymeric salicylaldimine Schiff bases via 
RAFT alternating copolymerization and they further confirmed the superb accuracy and sensitivity of copolymers compared with small molecule detection. ${ }^{40}$ However, almost all of the reported studies on polymer-based fluorescent chemosensors primarily focus on easy fabrication processes, high solubility, accuracy and sensitivity, but cytocompatibility has not been taken seriously.

To be used safely, it is absolutely necessary for probes to have excellent biocompatibility properties. Phosphorylcholine (PC) groups, a major headgroup in phospholipids, which are the main constituents of plasma membranes, have been often conjugated into different polymers to mimic membrane structure and have made quite good progress. ${ }^{48}$ 2-Methacryloyloxyethyl phosphorylcholine (MPC) is a methacrylate monomer with a phosphorylcholine group, which has been extensively synthesized to mimic cell membranes and is considered as a biocompatible material. On account of their simple molecular design and synthesis process, excellent biocompatibility, water solubility, and transparency in visible light, MPC polymers are considered promising in materials science and biomedical applications. In our previous studies, ${ }^{\mathbf{4 9}, 50}$ these polymers with PC shells exhibited great biostability and biocompatibility, which supported the polymers' normal functions in complex environments. Additionally, MPC polymers were also developed by Ji's group as a biocompatible imaging agent. ${ }^{51-54}$ It turned out that these biomimetic polymers were suitable for biological materials and imaging agents. Thus, the combination of salicylaldimine Schiff bases with MPC polymers would utilize well the advantages of both of their merits.

Herein, a biomimetic fluorescent chemosensor was designed and used for the delicate detection of zinc(II). To synthesize this copolymer, a three-step process was required. Firstly, ATRP polymerization was conducted with $N$-Boc-aminoethyl methacrylate and MPC using ethyl $\alpha$-bromoisobutyrate as the initiator to produce PNBAEMA-co-PMPC. Then, PNBAEMA- $c$-PMPC was deprotected to obtain PAEMA-co-PMPC. Lastly, salicylaldehyde and PAEMA-co-PMPC were connected by Schiff base bonds (PSaAEMA-co-PMPC). The polymer chemosensor could efficiently bind $\mathrm{Zn}^{2+}$ ions, which specifically led to a change in fluorescence intensity. Furthermore, the cytotoxicity and cell uptake behaviors of PSaAEMA-co-PMPC were investigated to evaluate the biological performance of this material (Scheme 1).

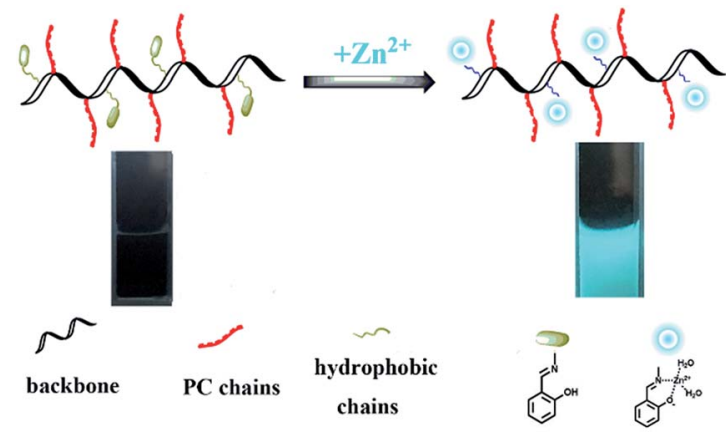

Scheme 1 Schematic illustration of PSaAEMA-CO-PMPC for zinc(॥) detection.

\section{Experimental}

\section{Materials}

Ethanolamine, $\mathrm{N}$-Boc-aminoethyl, methacryloyl chloride and ethyl $\alpha$-bromoisobutyrate were purchased from Aladdin. MPC was synthesized according to our previous studies. Chloride salts, $\mathrm{MgSO}_{4}$, and nitrate salts were used for all of the sensing experiments. Water was prepared by our own filtration system. The human umbilical vein endothelial cell line (HUVEC) and HeLa cells were obtained from the Cell Bank of the Chinese Science Academy, Shanghai, China. All of the reagents obtained from commercial sources were used as received without further purification.

\section{Instrumentations}

Absorption spectra were recorded on an Analytic-jena Specord S600 (Germany) spectrophotometer in absorbance mode using quartz cuvettes of $1 \mathrm{~cm}$ path length. ${ }^{1} \mathrm{H}$ NMR measurements were carried out on a Bruker AV400 spectrometer. A Perkin Elmer LS-55 spectrofluorometer was used to measure the fluorescence spectra. Fluorescent pictures were taken on a ZEISS Axio Scope Fluorescence Microscope.

\section{Synthesis of $N$-Boc-ethanolamine}

Ethanolamine $(1.10 \mathrm{~g}, 18.3 \mathrm{mmol})$ was added into $200 \mathrm{~mL}$ methanol and a solution of di-tert-butyl dicarbonate $(0.01 \mathrm{~mol})$ was added dropwise over a period of about $2 \mathrm{~h}$ at $0{ }^{\circ} \mathrm{C}$. After stirring for $24 \mathrm{~h}$, the solution was concentrated under reduced pressure. Then, the crude produce was extracted with methylene chloride three times. The extract was dried with anhydrous $\mathrm{Na}_{2} \mathrm{SO}_{4}$ and concentrated under vacuum. Yield: $80 \%$. ${ }^{1} \mathrm{H} \mathrm{NMR}$ $\left(500 \mathrm{MHz}, \mathrm{CDCl}_{3}\right):$ d $1.42\left(9 \mathrm{H},-\mathrm{C}\left(\mathrm{CH}_{3}\right)_{3}\right), 3.15\left(2 \mathrm{H}, \mathrm{HOCH}_{2}-\right.$ $\mathrm{CH}_{2} \mathrm{CO}-$ ), 3.67 (2H, $\mathrm{HOCH}_{2} \mathrm{CH}_{2} \mathrm{CO}-$ ).

\section{Synthesis of $N$-Boc-aminoethyl methacrylate}

$N$-Boc-aminoethyl methacrylate was synthesized by a condensation reaction between acyl chloride and hydroxyl groups. $\mathrm{N}$ Boc-aminoethyl (20.2 g, $0.1 \mathrm{~mol})$, triethylamine (10.1 g $0.1 \mathrm{~mol}$ ) and $300 \mathrm{~mL}$ of methylene chloride were added into a flask at room temperature, and a methylene chloride solution $(15 \mathrm{~mL})$ of methacryloyl chloride ( $8.32 \mathrm{~g}, 0.08 \mathrm{~mol}$ ) was added dropwise. After $12 \mathrm{~h}$ stirring, deionized water was added and extracted with DCM three times. The extract was dried with anhydrous $\mathrm{Na}_{2} \mathrm{SO}_{4}$ and concentrated under vacuum. Yield: 79\%. ${ }^{1} \mathrm{H}$ NMR $\left(500 \mathrm{MHz}, \mathrm{CDCl}_{3}\right)$ : d $1.42\left(9 \mathrm{H},-\mathrm{C}\left(\mathrm{CH}_{3}\right)_{3}\right), 1,91\left(3 \mathrm{H}, \mathrm{CH}_{2}=\right.$ $\left.\mathrm{CH}\left(\mathrm{CH}_{3}\right)^{-}\right) 3.15\left(2 \mathrm{H}, \mathrm{HOCH}_{2} \mathrm{CH}_{2} \mathrm{CO}-\right), 4.36\left(2 \mathrm{H},-\mathrm{OCH}_{2} \mathrm{CH}_{2} \mathrm{CO}-\right.$ ), 5.56, $6.12\left(2 \mathrm{H}, \mathrm{CH}_{2}=\mathrm{CH}\left(\mathrm{CH}_{3}\right)^{-}\right)$.

\section{Synthesis of $\mathbf{P}(\mathrm{N}$-Boc-aminoethyl methacrylate)-co-P(2- methacryloyloxyethyl phosphorylcholine) (PNBAEMA-co- PMPC)}

PNBAEMA-co-PMPC was synthesized by the ATRP polymerization of $N$-Boc-aminoethyl methacrylate and MPC using ethyl $\alpha$ bromoisobutyrate as the initiator. In a typical reaction, $N$-Bocaminoethyl methacrylate (4 g, $25 \mathrm{mmol})$, MPC (4 g, $25 \mathrm{mmol})$, 
ethyl $\alpha$-bromoisobutyrate (124 mg, $0.625 \mathrm{mmol}$ ), CuBr (89 mg, $0.625 \mathrm{mmol}$ ), PMDETA (216 mg, $1.25 \mathrm{mmol}$ ) and $10 \mathrm{~mL} \mathrm{DMSO} /$ $\mathrm{MeOH}(1: 1)$ were added into a $25 \mathrm{~mL}$ flask under a nitrogen atmosphere. The reaction mixture was degassed by three freezepump-thaw cycles and stirred at $30{ }^{\circ} \mathrm{C}$ for $12 \mathrm{~h}$. Then, the reaction mixture was exposed to air and the solution was diluted with $\mathrm{MeOH}$ and passed through silica gel column chromatography to remove the catalyst. The filtrate was concentrated and precipitated into ethyl ether and the precipitate was dried under vacuum. Yield: $65 \%$.

\section{Synthesis of $\mathbf{P}($ aminoethyl methacrylate)-co-P(2- methacryloyloxyethyl phosphorylcholine)trifluoroacetate salt (PAEMA-co-PMPC)}

$0.15 \mathrm{~g}$ PNBAEMA-co-PMPC was dissolved in $3 \mathrm{~mL}$ methanol and $3 \mathrm{~mL}$ DMSO in a $25 \mathrm{~mL}$ flask. Then, $6 \mathrm{~mL}$ TFA was added and stirred at room temperature for $5 \mathrm{~h}$. The reaction solution was concentrated under reduced pressure. Finally, the crude product was dialyzed against distilled water (MWCO 3500) for 2 days and lyophilized. Yield: 70\%.

\section{Synthesis of $\mathbf{P}(2$-salicylaldehyde-aminoethyl ethanolamine methacrylate)-co-P(2-methacryloyloxyethyl phosphorylcholine) (PSaAEMA-co-PMPC)}

PAEMA-co-PMPC (508 $\mathrm{mg}, 2 \mathrm{mmol})$ and anhydrous TEA $(0.55 \mathrm{~mL}, 4 \mathrm{mmol})$ were dissolved in $10 \mathrm{~mL}$ anhydrous methanol, and then salicylaldehyde $(0.23 \mathrm{~mL}, 2.2 \mathrm{mmol})$ was added. The reaction mixture was stirred at room temperature for $12 \mathrm{~h}$, and the solution was then concentrated under reduced pressure. The crude product was precipitated into ethyl ether. After drying for two days in a vacuum, a yellow powder was obtained. Yield: $70 \%$.

\section{Absorption and fluorescence measurements}

The copolymers (PSaAEMA-co-PMPC) were prepared and dissolved in PBS (20 mM; pH = 7.4) before use. Cationic solutions were prepared by dissolving metal salts in deionized water with a concentration of $0.1 \mathrm{M}$ and were diluted as required before use. A solution of the test sample $(4.0 \mathrm{~mL}, 20 \mu \mathrm{M}$ for $\mathrm{UV}$-Vis and $40 \mu \mathrm{M}$ for fluorescence) was prepared, and UV-Vis and fluorescence spectra were recorded at room temperature. The total volume of each ionic solution introduced to the test solution was no more than $25 \mu \mathrm{L}$, and the changes in fluorescence intensity were recorded after the solution was mixed for $10 \mathrm{~min}$ $\left(\lambda_{\mathrm{ex}}=368 \mathrm{~nm}\right)$.

\section{Cell cytotoxicity assay}

The cytotoxicity of PSaAEMA-co-PMPC was evaluated by an in vitro MTT assay. HUVEC cells and HeLa cells were seeded in 96well plates with $6 \times 10^{3}$ cells per well. After incubation for $24 \mathrm{~h}$, the culture medium was replaced by fresh medium with PSaAEMA-co-PMPC at different concentrations (10 to $1000 \mu \mathrm{g}$ $\left.\mathrm{mL}^{-1}\right)$. After the cells were incubated for $48 \mathrm{~h}$, the cells were subjected to an MTT assay.

\section{Cell imaging}

HeLa cells were used for cell imaging in this study. HeLa cells were seeded in 24 -well plates with $2 \times 10^{4}$ cells per well. After incubation for $24 \mathrm{~h}$, the culture medium was replaced by fresh medium with PSaAEMA-co-PMPC $(20 \mu \mathrm{M})$. After incubation for a further $1 \mathrm{~h}$, the cells were washed with cold PBS three times. Then the cells were further treated with $\mathrm{ZnCl}_{2}(25 \mathrm{mM})$ plus sodium pyrithione $(5 \mathrm{mM})$. After this, the cells were washed with cold PBS three times and fixed with $4 \%$ formaldehyde for 15 min. Finally, the cells were observed using a fluorescence microscope.

\section{Results and discussion}

\section{Synthesis of $\mathrm{Zn}^{2+}$ probe}

The synthetic route for the preparation of the PSaAEMA-coPMPC polymer is illustrated in Scheme 2. This copolymer was prepared in three steps. First, $\mathrm{N}$-Boc-aminoethyl methacrylate was synthesized by $N$ (Boc) protected ethanolamine and methacryloylchloride, and the product was sequentially polymerized with MPC via ATRP using EBIB as the initiator. Then, deprotection of the $N$-Boc of the copolymer using TFA exposed a free amine group which could react with salicylaldehyde. Finally, salicylaldehyde was grafted to the copolymer through Schiff base bonds. Fig. S1 and S2 $\uparrow$ show the ${ }^{1} \mathrm{H}$ NMR spectra of $N$ (Boc) protected ethanolamine and $N$-Boc-aminoethyl methacrylate, respectively. The results indicated that the monomer was prepared successfully. Moreover, the ${ }^{13} \mathrm{C}$ NMR spectrum (Fig. S3†) further confirmed the correctness of the structure. Fig. 1 shows the ${ }^{1} \mathrm{H}$ NMR spectrum of the polymer probe. The signal at $\delta=8.5 \mathrm{ppm}(j)$ was assigned to the characteristic peaks of the Schiff bases, and the signal at $\delta=3.6 \mathrm{ppm}(b)$ was assigned to the methylene protons of the choline units. The ratio of $j$ and $b$ is roughly equal to $1: 2$, which suggested that the two units were equivalent in PSaAEMA-co-PMPC. As the Mn content of PMPC-co-PMEMA could not be determined by GPC, the Mn content was estimated from the ${ }^{1} \mathrm{H}$ NMR spectrum by comparing the proportion of the signals at $\delta=3.40$ (EBiB) and



Scheme 2 Detailed synthetic route of PSaAEMA-co-PMPC. 


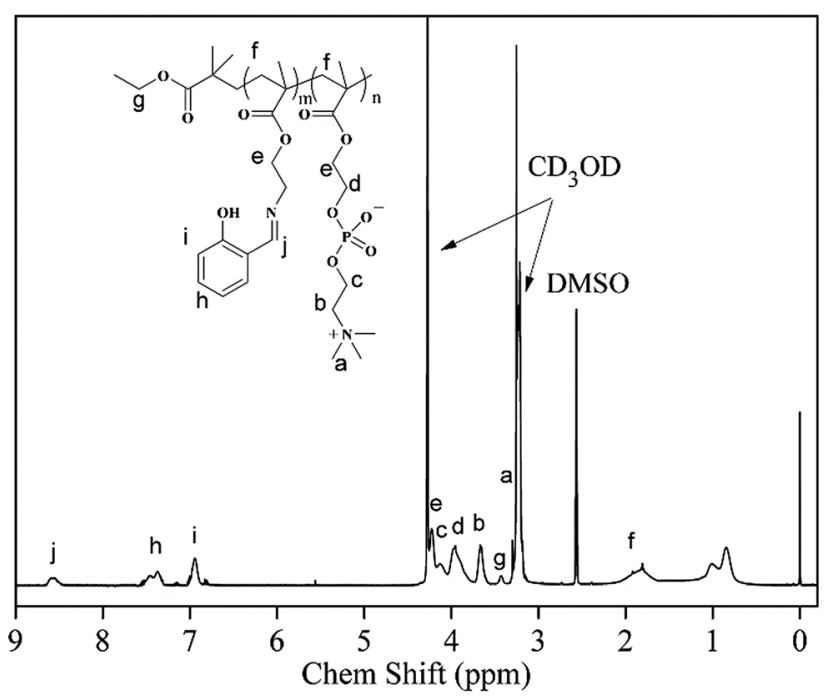

Fig. $1{ }^{1} \mathrm{H}$ NMR spectrum of PSAAEMA-CO-PMPC in CD3OD/DMSO$d_{6}$.

$\delta=3.6 \mathrm{ppm}$ (b); the Mn content of PMPC-b-PMEMA was about $6494 \mathrm{~g} \mathrm{~mol}^{-1}$.

\section{$\mathrm{Zn}^{2+}$ ion recognition}

It is known that salicylaldimine Schiff bases can coordinate with various metal ions, especially zinc complexes, which often leads to strong fluorescence emission. Therefore, we designed a monomer that possessed an amine group to form a Schiff base with salicylaldehyde and speculated that this part of the copolymer would show no fluorescence prior to the addition of zinc ions, but once the zinc ions were added, the copolymer would emit intense fluorescence. To verify our presumption, we examined the UV-Vis spectra of the copolymer with a gradual addition of $\mathrm{Zn}^{2+}$. Fig. 2 shows the absorption changes of the

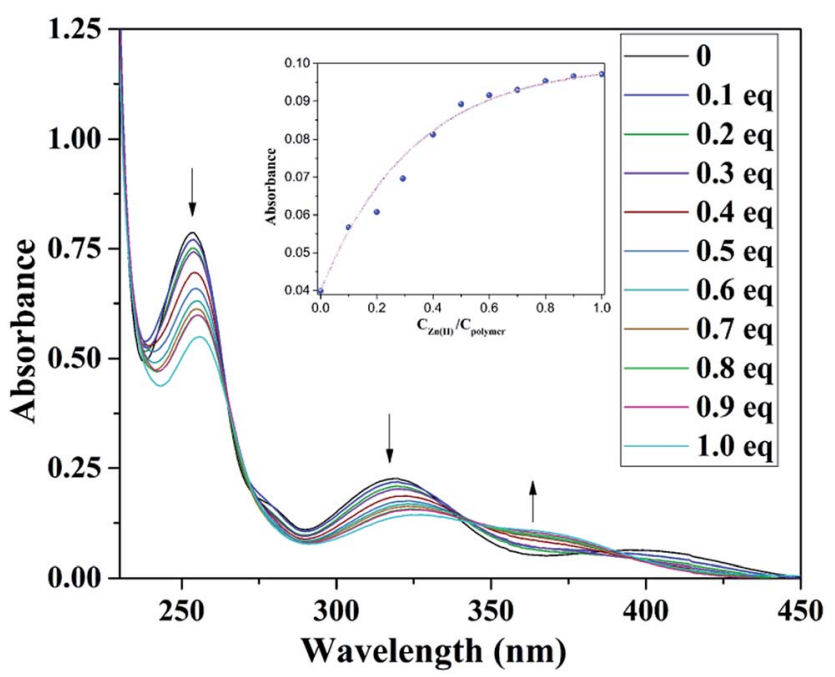

Fig. 2 Absorption spectra of $10 \mathrm{~mol} \mathrm{~L}^{-1}$ copolymer with the addition of $0-15 \mathrm{~mol} \mathrm{~L} \mathrm{~L}^{-1} \mathrm{Zn}^{2+}$. Inset: The absorbance ratio $\left(A_{383} / A_{346}\right)$ as a function of $\mathrm{Zn}^{2+}$ concentration. copolymer upon a gradual addition of $0-1.0$ equiv. $\mathrm{Zn}^{2+}$. It can be seen that with the addition of $\mathrm{Zn}^{2+}$ into the copolymer solution, the absorption bands at 254 and $316 \mathrm{~nm}$ decreased gradually, and new absorption bands at $363 \mathrm{~nm}$ emerged simultaneously. Three isosbestic points could be clearly seen (Fig. 2). The absorption bands at $316 \mathrm{~nm}$ gradually decrease which was attributed to the $n-\pi *$ transition of $\mathrm{C}=\mathrm{N}$. The above results indicated a conversion of the Schiff bases to Schiff base$\mathrm{Zn}^{2+}$ complexes. No further changes were observed in the absorbance spectra with up to 1 equiv. $\mathrm{Zn}^{2+}$ addition, revealing that the binding ratio between $\mathrm{Zn}^{2+}$ and the copolymer should be $1: 1$.

To test the sensing ability of PSaAEMA-co-PMPC for $\mathrm{Zn}^{2+}$ in aqueous solutions, fluorescence titration of this copolymer with a gradual addition of $\mathrm{Zn}^{2+}$ was investigated and the results are shown in Fig. 3. The addition of $\mathrm{Zn}^{2+}$ leads to an increase in $450 \mathrm{~nm}$ emission intensity, which is ascribed to the formation of zinc complexes, which inhibit $\mathrm{C}=\mathrm{N}$ isomerization and cause a chelation-enhanced fluorescence effect. In the fluorescence spectra under the same test conditions, more than an 800-fold fluorescence enhancement at around $450 \mathrm{~nm}$ occurred upon the addition of $\mathrm{Zn}^{2+}(0.1$ equiv., Fig. 3$)$. This increase is similar to that with the addition of 1 equiv. of $\mathrm{Zn}^{2+}$. As shown in the inset, a linear relationship is observed between the intensity and the amount of $\mathrm{Zn}^{2+}$ in the range of 0-0.7 equiv., which corresponds to $0-14 \mathrm{mM} \mathrm{Zn}^{2+}$ (linearly dependent coefficient: $\left.R^{2}=0.997\right)$. The linear fitting of the titration curve further confirmed that the binding of the copolymer and $\mathrm{Zn}^{2+}$ was most probably a $1: 1$ metal-to-ligand ratio. This indicates that the copolymer has potential for application in the quantitative determination of $\mathrm{Zn}^{2+}$ in aqueous solutions.

Then, the PSaAEMA-co-PMPC solution was treated with various metal ions to verify the fluorescence response behavior. The measurements were conducted with excitation at $368 \mathrm{~nm}$ to examine the ion selective ability of the copolymer in aqueous solutions. As shown in Fig. $4 \mathrm{~A}$, the addition of $\mathrm{Zn}^{2+}$ causes an

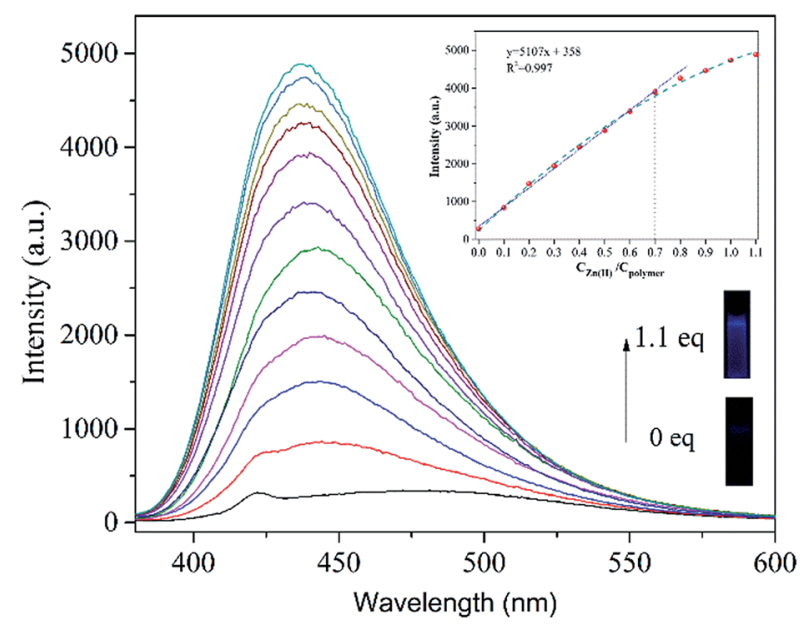

Fig. 3 Fluorescence spectra ( $\lambda_{\mathrm{ex}}=368 \mathrm{~nm}$ ) of (PSaAEMA-CO-PMPC) $(20 \mu \mathrm{M})$ with different concentrations of $\mathrm{Zn}^{2+}$; inset: the fluorescence intensity at $450 \mathrm{~nm}$ as a function of $\mathrm{Zn}^{2+}$ concentration. Excitation was at $368 \mathrm{~nm}$. 


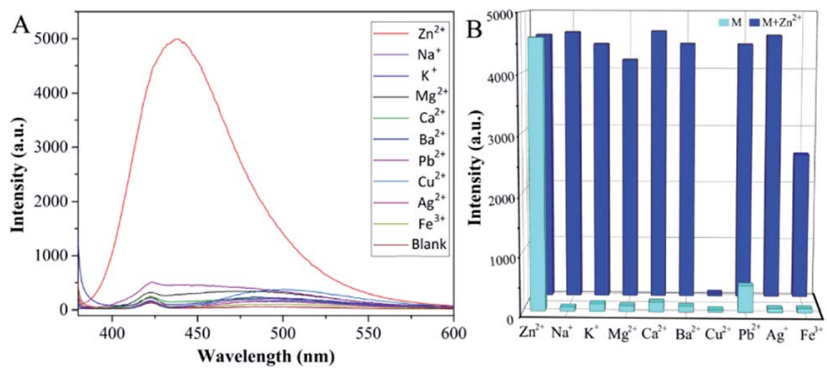

Fig. 4 (A) Fluorescence spectra of the fluorescence intensity of (PSaAEMA-CO-PMPC) $(20 \mu \mathrm{M})$ upon the addition of 1.0 equiv. of various metal ions. (B) Corresponding fluorescence intensity of (PSAAEMA-CO-PMPC) with different metal ions in the absence and presence of $\mathrm{Zn}^{2+}$. $\left(\lambda_{\mathrm{ex}}=368 \mathrm{~nm}\right)$.

obvious 5000-fold emission enhancement at around $450 \mathrm{~nm}$. However, the emission intensities at around $450 \mathrm{~nm}$ were barely enhanced with the addition of $\mathrm{Na}^{+}, \mathrm{K}^{+}, \mathrm{Mg}^{2+}, \mathrm{Ca}^{2+}, \mathrm{Ba}^{2+}, \mathrm{Pb}^{2+}$, $\mathrm{Cu}^{2+}, \mathrm{Ag}^{2+}$ and $\mathrm{Fe}^{3+}$. Therefore, the copolymer exhibits an excellent selectivity toward $\mathrm{Zn}^{2+}$ binding. Fig. $4 \mathrm{~B}$ shows the fluorescence response of PSaAEMA-co-PMPC with different metal ions in the absence and presence of $\mathrm{Zn}^{2+}$. Most of the representative ions like $\mathrm{Na}^{+}, \mathrm{K}^{+}, \mathrm{Ba}^{2+}, \mathrm{Pb}^{2+}$ and $\mathrm{Ag}^{2+}$ cause a slight interference in $\mathrm{Zn}^{2+}$ detection. The addition of $\mathrm{Ca}^{2+}$ causes a small increase in the emission intensity, whereas $\mathrm{Mg}^{2+}$ and $\mathrm{Fe}^{3+}$ partially quench the fluorescence, which is due to their competitive coordination to $\mathrm{Zn}^{2+}$, as verified by the previous reports. Besides, the presence of $\mathrm{Cu}^{2+}$ induces absolute quenching, since $\mathrm{Cu}^{2+}$ has a higher binding constant with the salicylaldimine Schiff bases as well as a heavy atom quenching effect.

\section{Living cell imaging}

Before PSaAEMA-co-PMPC can be used as a bio-imaging probe, it is necessary to evaluate its cytotoxicity. For this purpose, cultured HeLa cells and HUVEC cells were incubated with

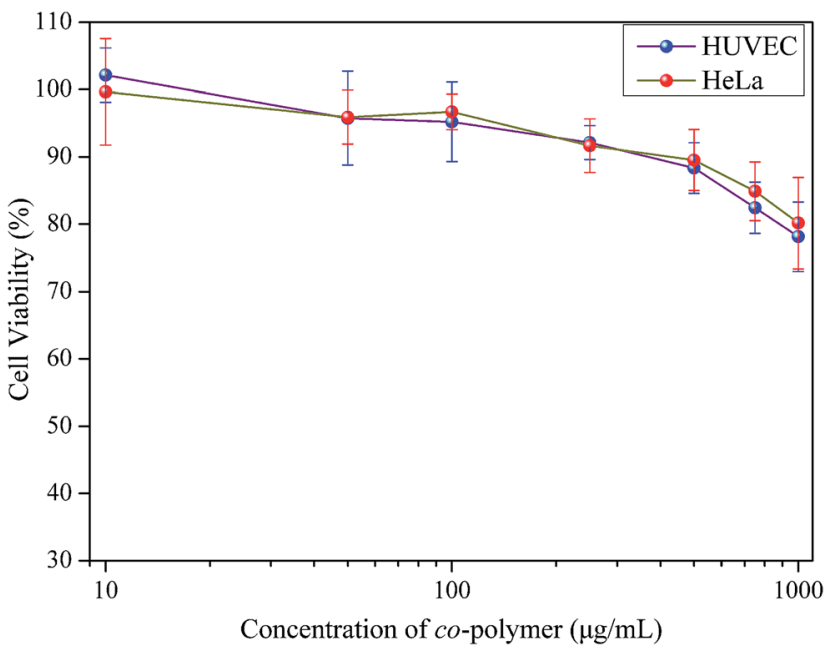

Fig. 5 Cell cytotoxicity of HeLa and HUVEC cells incubated with various concentrations of PSaAEMA-CO-PMPC.

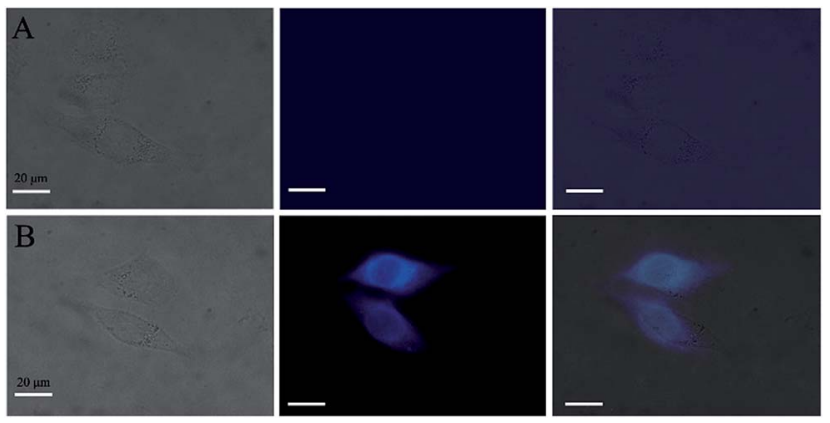

Fig. 6 Fluorescence images of live HeLa cells. From left to right are bright field images, fluorescence images and overlay images. (A) HeLa cells were incubated with PSaAEMA-CO-PMPC for $30 \mathrm{~min}$ and washed with PBS; (B) HeLa cells were incubated with PSaAEMA-CO-PMPC, and then with $\mathrm{Zn}^{2+}\left(10 \mu \mathrm{mol} \mathrm{L}{ }^{-1}\right)$ and pyrithione $\left(10 \mu \mathrm{mol} \mathrm{L}{ }^{-1}\right)$ for $20 \mathrm{~min}$ and washed with PBS.

different concentrations of copolymer solution (from 10 to $1000 \mu \mathrm{g} \mathrm{mL}^{-1}$ ) for $48 \mathrm{~h}$. Subsequently, an MTT assay was carried out. Fig. 5 demonstrated that, even when treated with a certain high concentration of this copolymer $\left(1000 \mu \mathrm{g} \mathrm{mL}{ }^{-1}\right), 80 \%$ of cells were still alive. This result indicates that PSaAEMA-coPMPC has a low cytotoxicity to cells and is suitable for intracellular imaging.

Then, the application of PSaAEMA-co-PMPC for the fluorescence imaging of $\mathrm{Zn}^{2+}$ in live HeLa cells was investigated. As observed by laser scanning confocal microscopy, HeLa cells incubated with $20 \mu \mathrm{g} \mathrm{mL}{ }^{-1}$ PSaAEMA-co-PMPC for $20 \mathrm{~min}$ at $37^{\circ} \mathrm{C}$ showed no intracellular fluorescence. Then, the cells were cultured with $10 \mu \mathrm{mol} \mathrm{L}{ }^{-1} \mathrm{Zn}^{2+}$ and $10 \mu \mathrm{mol} \mathrm{L}{ }^{-1}$ pyrithione, which is a zinc selective ionophore, for $20 \mathrm{~min}$ at $37^{\circ} \mathrm{C}$ and then washed with PBS three times. A significant fluorescence increase from the intracellular area was shown (Fig. 6), and we could clearly observe the entire cellular outline. These results suggested that PSaAEMA-co-PMPC could be used as an effective chemosensor for $\mathrm{Zn}^{2+}$ imaging in living cells.

\section{Conclusion}

In summary, we have developed a novel salicylaldehyde based chemosensor PSaAEMA-co-PMPC, which displays strong fluorescence with high selectivity and sensitivity for $\mathrm{Zn}^{2+}$ compared to other competing metal ions. The sensor gives a fluorescence response in an aqueous solution upon binding with zinc(II) in a $1: 1$ ratio. Moreover, due to the structure of $\mathrm{PC}$, the cytocompatibility of the copolymer was excellent, which is perfect for biological applications. Hence, the biological application of PSAAEMA-co-PMPC was evaluated for the detection of $\mathrm{Zn}^{2+}$ in living cells. The results showed that it had low cytotoxicity and excellent cell fluorescence illumination and suggested that PSAAEMA-co-PMPC was cell-permeable and capable of the intracellular detection of $\mathrm{Zn}^{2+}$.

\section{Conflicts of interest}

There are no conflicts to declare. 


\section{Acknowledgements}

This work was funded by the National Natural Science Foundation of China (No. 51773129, 51503130), the Support Plan of Science and Technology Department of Sichuan Province, China (2017GZ0129, 2018SZ0174), the International Science and Technology Cooperation Program of Chengdu (2017-GH0200068-HZ), the Postdoctoral Research Foundation of Sichuan University (2018SCU12049) and was supported by the Graduate Student's Research and Innovation Fund of Sichuan University (2018YJSY084).

\section{Notes and references}

1 J. R. Burdo and J. R. Connor, BioMetals, 2003, 16, 63-75.

2 E. J. Martinez-Finley, S. Chakraborty, S. J. B. Fretham and M. Aschner, Metallomics, 2012, 4, 593-605.

3 D. J. Bonda, H. G. Lee, J. A. Blair, X. W. Zhu, G. Perry and M. A. Smith, Metallomics, 2011, 3, 267-270.

4 M. Tyszka-Czochara, A. Grzywacz, J. Gdula-Argasinska, T. Librowski, B. Wilinski and W. Opoka, Acta Pol. Pharm., 2014, 71, 369-377.

5 S. L. Sensi, P. Paoletti, J. Y. Koh, E. Aizenman, A. I. Bush and M. Hershfinkel, J. Neurosci., 2011, 31, 16076-16085.

6 Q. Y. Cao, R. Jiang, M. Liu, Q. Wan, D. Xu, J. Tian, H. Huang, Y. Wen, X. Zhang and Y. Wei, Mater. Sci. Eng., C, 2017, 80, 578-583.

7 Q. Y. Cao, R. Jiang, M. Liu, Q. Wan, D. Xu, J. Tian, H. Huang, Y. Wen, X. Zhang and Y. Wei, Mater. Sci. Eng., C, 2017, 80, 411-416.

8 H. Huang, D. Xu, M. Liu, R. Jiang, L. Mao, Q. Huang, Q. Wan, Y. Wen, X. Zhang and Y. Wei, Mater. Sci. Eng., C, 2017, 78, 862-867.

9 R. Jiang, L. Huang, M. Liu, F. Deng, H. Huang, J. Tian, Y. Wen, Q. Y. Cao, X. Zhang and Y. Wei, Mater. Sci. Eng., C, 2018, 83, 115-120.

10 R. Jiang, M. Liu, H. Huang, L. Huang, Q. Huang, Y. Wen, Q.-y. Cao, J. Tian, X. Zhang and Y. Wei, Dyes Pigm., 2018, 149, 581-587.

11 R. Jiang, M. Liu, C. Li, Q. Huang, H. Huang, Q. Wan, Y. Wen, Q. Y. Cao, X. Zhang and Y. Wei, Mater. Sci. Eng., C, 2017, 80, 708-714.

12 M. Liu, G. Zeng, K. Wang, Q. Wan, L. Tao, X. Zhang and Y. Wei, Nanoscale, 2016, 8, 16819-16840.

13 Y. Liu, L. Mao, X. Liu, M. Liu, D. Xu, R. Jiang, F. Deng, Y. Li, X. Zhang and Y. Wei, Mater. Sci. Eng., C, 2017, 79, 590-595.

14 L. Mao, M. Liu, L. Huang, D. Xu, Q. Wan, G. Zeng, Y. Dai, Y. Wen, X. Zhang and Y. Wei, Mater. Sci. Eng., C, 2017, 79, 596-604.

15 Y. Q. Niu, T. He, J. Song, S. P. Chen, X. Y. Liu, Z. G. Chen, Y. J. Yu and S. G. Chen, Chem. Commun., 2017, 53, 75417544.

16 S. Yu, D. Xu, Q. Wan, M. Liu, J. Tian, Q. Huang, F. Deng, Y. Wen, X. Zhang and Y. Wei, Mater. Sci. Eng., C, 2017, 78, 191-197.

17 X. Zhang, K. Wang, M. Liu, X. Zhang, L. Tao, Y. Chen and Y. Wei, Nanoscale, 2015, 7, 11486-11508.
18 X. Zhang, S. Wang, L. Xu, L. Feng, Y. Ji, L. Tao, S. Li and Y. Wei, Nanoscale, 2012, 4, 5581-5584.

19 P. Chabosseau, J. Woodier, R. Cheung and G. A. Rutter, Metallomics, 2018, 10, 229-239.

20 M. J. Chang and M. H. Lee, Dyes Pigm., 2018, 149, 915-920.

21 K. Du, S. Z. Niu, X. Z. Chen and P. F. Zhang, Tetrahedron Lett., 2018, 59, 356-360.

22 J. Kim, E. G. Camemolla, C. DeVaul, A. M. Shaltout, D. Faccio, V. M. Shalaev, A. V. Kildishev, M. Ferrera and A. Boltasseva, Nano Lett., 2018, 18, 740-746.

23 S.-R. Liu and S.-P. Wu, Sens. Actuators, B, 2012, 171-172, 1110-1116.

24 R. Mehta, M. H. Qureshi, M. K. Purchal, S. M. Greer, S. Z. Gong, C. Ngo and E. L. Que, Chem. Commun., 2018, 54, 5442-5445.

25 V. C. Pierre, S. M. Harris and S. L. Pailloux, Acc. Chem. Res., 2018, 51, 342-351.

26 D. Chen, K. P. Taylor, Q. Hall and J. M. Kaplan, Genetics, 2016, 204, 1151-1159.

27 W. H. Hsieh, C.-F. Wan, D.-J. Liao and A.-T. Wu, Tetrahedron Lett., 2012, 53, 5848-5851.

28 M. Kumar, A. Kumar, M. K. Singh, S. K. Sahu and R. P. John, Sens. Actuators, B, 2017, 241, 1218-1223.

29 Z. Liu, C. Zhang, Y. Chen, W. He and Z. Guo, Chem. Commun., 2012, 48, 8365-8367.

30 Z. Liu, C. Zhang, Y. Chen, F. Qian, Y. Bai, W. He and Z. Guo, Chem. Commun., 2014, 50, 1253-1255.

$31 \mathrm{X}$. Wu, N. Xu, Z. Zhu, Y. Cai, Y. Zhao and D. Wang, Polym. Chem., 2014, 5, 1202-1209.

32 Y. Zhou, Z. X. Li, S. Q. Zang, Y. Y. Zhu, H. Y. Zhang, H. W. Hou and T. C. Mak, Org. Lett., 2012, 14, 1214-1217.

33 J. Zhu, Y. Zhang, Y. Chen, T. Sun, Y. Tang, Y. Huang, Q. Yang, D. Ma, Y. Wang and M. Wang, Tetrahedron Lett., 2017, 58, 365-370.

34 S. Erdemir and B. Tabakci, Dyes Pigm., 2018, 151, 116-122.

35 Z. Y. Li, H. K. Su, K. Zhou, B. Z. Yang, T. X. Xiao, X. Q. Sun, J. L. Jiang and L. Y. Wang, Dyes Pigm., 2018, 149, 921-926.

36 Y. Y. Liu, Y. Y. Li, Q. Feng, N. Li, K. Li, H. W. Hou and B. Zhang, Luminescence, 2018, 33, 29-33.

37 S. Sakunkaewkasem, A. Petdum, W. Panchan, J. Sirirak, A. Charoenpanich, T. Sooksimuang and N. Wanichacheva, ACS Sens., 2018, 3, 1016-1023.

38 X. Chen, N. Xu, N. Li, L. Lu, Y. Cai, Y. Zhao and D. Wang, Soft Matter, 2013, 9, 1885-1894.

39 K. Johmoto, A. Sekine and H. Uekusa, Cryst. Growth Des., 2012, 12, 4779-4786.

40 S. Wang, B. Wu, F. Liu, Y. Gao and W. Zhang, Polym. Chem., 2015, 6, 1127-1136.

41 B. Wu, L. Xu, S. Wang, Y. Wang and W. Zhang, Polym. Chem., 2015, 6, 4279-4289.

42 J. Xu, R. Yan, H. Wang, Z. Du, J. Gu, X. Cheng and J. Xiong, RSC Adv., 2018, 8, 6798-6804.

43 H. Wang, Y. Wu, G. Liu, Z. Du and X. Cheng, Macromol. Chem. Phys., 2016, 217, 2004-2012.

44 F. D. Jochum and P. Theato, Macromolecules, 2009, 42, 59415945. 
45 X. W. Wu, N. Xu, Z. G. Zhu, Y. L. Cai, Y. Zhao and D. J. Wang, Polym. Chem., 2014, 5, 1202-1209.

46 H. A. Gao, G. H. Liu, X. J. Chen, Z. H. Hao, J. Y. Tong, L. C. Lu, Y. L. Cai, F. Long and M. Q. Zhu, Macromolecules, 2010, 43, 6156-6165.

47 X. J. Chen, N. Xu, N. Li, L. C. Lu, Y. L. Cai, Y. Zhao and D. J. Wang, Soft Matter, 2013, 9, 1885-1894.

48 Y. Iwasaki and K. Ishihara, Sci. Technol. Adv. Mater., 2012, 13, 064101.

49 H. Wang, J. Xiong, G. Liu and Y. Wang, Macromol. Chem. Phys., 2016, 217, 2049-2055.
50 H. B. Wang, G. Y. Liu, S. H. Dong, J. J. Xiong, Z. L. Dua and X. Cheng, J. Mater. Chem. B, 2015, 3, 7401-7407.

51 D. D. Chen, M. D. Wu, B. C. Li, K. F. Ren, Z. K. Cheng, J. Ji, Y. Li and J. Q. Sun, Adv. Mater., 2015, 27, 5882-5888.

52 X. S. Liu, H. Y. Huang, Q. Jin and J. Ji, Langmuir, 2011, 27, 5242-5251.

53 G. Y. Liu, L. P. Lv, C. J. Chen, X. S. Liu, X. F. Hu and J. Ji, Soft Matter, 2011, 7, 6629-6636.

54 Y. J. Chen, Y. Wang, H. B. Wang, F. Jia, T. J. Cai, J. Ji and Q. Jin, Polymer, 2016, 97, 449-455. 